\title{
Comparative efficacy and safety of the fixed versus unfixed combination of latanoprost and timolol in Chinese patients with open-angle glaucoma or ocular hypertension
}

Jia-Liang Zhao ${ }^{1 *}$, Jian $\mathrm{Ge}^{2}$, Xiao-Xin $\mathrm{Li}^{3}$, Yu-Min Li ${ }^{4}$, Yao-Hua Sheng ${ }^{5}$, Nai-Xue Sun ${ }^{6}$, Xing-Huai Sun ${ }^{7}, \mathrm{Ke} \mathrm{Yao}^{8}$ and Zheng Zhong ${ }^{9}$, for the Xalacom Study Group in China

\begin{abstract}
Background: A noninferiority trial was conducted to evaluate the efficacy of a single evening dose of fixedcombination latanoprost $50 \mu \mathrm{g} / \mathrm{mL}$ and timolol $0.5 \mathrm{mg} / \mathrm{mL}$ (Xalacom ${ }^{\circledR}$; LTFC), in Chinese patients with primary open-angle glaucoma (POAG) or ocular hypertension $(\mathrm{OH})$ who were insufficiently controlled on $\beta$-blocker monotherapy or $\beta$-blocker-based dual therapy.
\end{abstract}

Methods: This 8-week, randomized, open-label, parallel-group, noninferiority study compared once-daily evening dosing of LTFC with the unfixed combination of latanoprost, one drop in the evening, and timolol, one drop in the morning (LTUFC). The primary efficacy endpoint was the mean change from baseline to week 8 in diurnal intraocular pressure (IOP; mean of 8 AM, 10 AM, 2 PM, 4 PM IOPs). LTFC was considered noninferior to LTuFC if the upper limit of the $95 \%$ confidence interval (Cl) of the difference was $<1.5 \mathrm{mmHg}$ (analysis of covariance).

Results: Baseline characteristics were similar for LTFC ( $\mathrm{N}=125$; POAG, 70\%; mean IOP, $25.8 \mathrm{mmHg}$ ) and LTuFC ( $\mathrm{N}$ $=125 ;$ POAG, 69\%; mean IOP, $26.0 \mathrm{mmHg}$ ). Mean diurnal IOP changes from baseline to week 8 were $-8.6 \mathrm{mmHg}$ with LTFC and $-8.9 \mathrm{mmHg}$ with LTUFC (between-treatment difference: $0.3 \mathrm{mmHg} ; 95 \%-\mathrm{Cl},-0.3$ to 1.0 ). Both treatments were well tolerated.

Conclusions: A single evening dose of LTFC was at least as effective as the unfixed combination of latanoprost in the PM and timolol in the AM in reducing IOP in Chinese subjects with POAG or OH whose IOP was insufficiently reduced with $\beta$-blocker monotherapy or $\beta$-blocker-based dual therapy. LTFC is an effective and well tolerated once-daily treatment for POAG and $\mathrm{OH}$.

Trial registration: Clinicaltrials.gov registration: NCT00219596

\section{Background}

In China, 158 million people are over the age of 60, with the number projected to increase to approximately 250 million by the year 2020 [1]. As the median age rapidly rises, age-related diseases of the eye are emerging as a major public health issue. Primary open-angle glaucoma (POAG) in Chinese individuals over the age of 40 years has an estimated prevalence of approximately $1.5 \%$ to

\footnotetext{
* Correspondence: zhaojialiang@medmail.com.cn

${ }^{1}$ Chinese Academy of Medical Sciences, Peking Union Medical College Hospital, Beijing, China

Full list of author information is available at the end of the article
}

2\% [2]. Reliable data concerning the prevalence in China of ocular hypertension $(\mathrm{OH})$, characterized by intraocular pressure $(\mathrm{IOP})>21 \mathrm{mmHg}$ without ocular nerve damage and visual field loss, are not available.

Monotherapy with $\beta$-adrenergic antagonists such as timolol $0.5 \%$, which lowers IOP levels by reducing aqueous humor outflow [3-5], continues to be among the most widely used approaches to treating POAG and $\mathrm{OH}$ in China. Although timolol generally is well tolerated, a significant proportion of timolol-treated patients does not achieve targeted IOP levels [6], and approximately one-third require a change in or addition to initial 
timolol monotherapy after 1 year, a proportion that increases to one-half after 2 years [7].

Latanoprost $0.005 \%$, a selective prostaglandin $F_{2 \alpha}$ receptor agonist that has a mechanism of action complementary to that of timolol (i.e., acts mainly by increasing outflow) [8], has been shown to be an effective treatment for POAG and $\mathrm{OH}$ as monotherapy [9-12]. Results of a cross-national meta-analysis suggested that there is an efficacy advantage for latanoprost compared to timolol in Chinese patients with POAG that is independent of other clinical and demographic variables [13].

Patients who do not achieve target IOP levels with a single ocular hypotensive agent often are prescribed concomitant therapy with a medication that has a different mechanism of action, an approach supported by the American Academy of Ophthalmology [14] and the European Glaucoma Society [15]. In patients with POAG or OH whose IOP is not sufficiently controlled on timolol monotherapy, concomitant treatment with latanoprost has demonstrated additive IOP-reducing efficacy [10,16-18]. Moreover, in a double-masked comparison, evening dosing of fixed-combination latanoprost/timolol (Xalacom ${ }^{\mathbb{B}}$; LTFC) was found to be at least as effective as latanoprost instilled once daily in the evening and timolol administered in both the morning and evening [19].

The purpose of the current study in Chinese patients was to evaluate the efficacy and tolerability of a single evening dose of LTFC versus the unfixed combination of latanoprost administered once daily in the evening and timolol dosed once daily in the morning (LTuFC).

\section{Methods}

\section{Study design}

This was an 8-week, randomized, open-label, parallelgroup study conducted at 8 sites in China between June 30, 2005, and September 13, 2006 (NCT00219596). The study was conducted in accordance with the tenets of the Declaration of Helsinki and with all Chinese regulatory requirements and was approved by the Ethics Committee of Peking Union Medical College Hospital, Beijing, China. Written informed consent was obtained from study participants prior to study entry.

\section{Subjects}

Males or females were eligible if they were 18 years of age or older, were diagnosed with POAG or $\mathrm{OH}$ and had been treated for at least the 4 weeks immediately prior to screening with $\beta$-blocker monotherapy or with a $\beta$-blocker-based dual therapy. At the screening visit, the IOP was required to be $\geq 17$ and $\leq 35 \mathrm{mmHg}$ in at least 1 eye at both the $8 \mathrm{AM}$ and $10 \mathrm{AM}$ measurement time points. At the baseline visit after washout (described below), IOP measured at 10 AM was required to be $\geq 21$ and $\leq 35 \mathrm{mmHg}$ and $\geq 25 \%$ higher than the IOP level at screening in at least 1 eye (same eye at both time points) for $\beta$-blocker monotherapy users, or $\geq 21$ and $\leq 35 \mathrm{mmHg}$ and $\geq 30 \%$ higher than the IOP at screening in at least 1 eye (same eye at both time points) for those treated with $\beta$-blocker-based dual therapy.

Potential subjects were excluded if they met any of the following criteria: (1) closed/barely open anterior chamber angle or a history of acute angle-closure glaucoma; (2) ocular surgery in one or both eyes within 3 months prior to the screening visit; (3) any condition in one or both eyes that could prevent reliable applanation tonometry; (4) ocular inflammation/infection occurring within 1 month prior to the screening visit; (5) use, or planned use, of any topical or systemic medication known to affect IOP; (6) known hypersensitivity to benzalkonium chloride or to any component of the study drug solutions; (7) any ocular or medical condition in which treatment with $\beta$-blocking agents is contraindicated; and (8) any acute or uncontrolled medical or psychiatric illness. Pregnant or lactating women or women of childbearing potential not using an acceptable method of contraception also were excluded.

\section{Treatments and Assessments}

After initial screening, subjects completed a washout period that varied in length depending on the current drug as follows: 4 weeks for $\beta$-adrenergic antagonists and prostaglandin analogs (including latanoprost, bimatoprost, travoprost, and unoprostone); 2 weeks for adrenergic agonists; and 5 days for cholinergic agonists and carbonic anhydrase inhibitors.

After the washout period, all eligible subjects were assigned a randomization number by the site coordinator. Subjects were randomized in a 1:1 ratio according to a computer-generated pseudorandomization number generator using random permuted blocks with a fixed block size to the LTFC or LTuFC group. Each site was provided with sealed envelopes marked with sequential randomization numbers containing the name of the treatment to which the subject was randomized. Envelopes were returned to the sponsor at study completion. Randomized subjects received either one drop of LTFC at approximately $8 \mathrm{PM}$ or the LTuFC consisting of one drop of latanoprost $0.005 \%$ at approximately $8 \mathrm{PM}$ and one drop of timolol $0.5 \%$ at approximately $8 \mathrm{AM}$. At the baseline visit, subjects received study medication sufficient for 4 weeks; at the week 4 visit, medication sufficient for the remaining 4 weeks of the study was dispensed. Postbaseline study visits occurred at weeks 1 , $2,4,6$, and 8 . Study medication was discontinued at week 8 whereupon subjects continued therapy with 
available medication. Subjects had a final follow-up visit at week 10.

IOP was measured at $8 \mathrm{AM}$ and $10 \mathrm{AM}$ at screening; at $8 \mathrm{AM}, 10 \mathrm{AM}, 2 \mathrm{PM}$, and $4 \mathrm{PM}$ at baseline and week 8 (or early discontinuation); and at 8 AM only at weeks $1,2,4$, and 6 . At each measurement time point, two assessments were performed in each eye, alternating between eyes, and the IOP at a given time point was defined as the average of the two measures. For each subject, IOP assessments were made by the same examiner using the same calibrated Goldmann applanation tonometer at each visit. Additional evaluations performed at each visit included assessment of systemic and ocular adverse events; recording of vital signs; visual acuity measurement; and lid, slit lamp, and ophthalmoscopy examinations of eye structures. Visual field examinations were performed at screening and week 8 .

\section{Endpoints and analyses}

The primary efficacy endpoint was change from baseline in mean diurnal IOP at week 8 . If only one eye was eligible, the diurnal IOP for each measurement day was the mean of IOP measurements at $8 \mathrm{AM}, 10 \mathrm{AM}, 2 \mathrm{PM}$, and 4 PM of the study eye. If both eyes were eligible, the diurnal IOP for each measurement day was calculated as the mean of diurnal IOP levels across study eyes.

The study was designed to evaluate whether LTFC was noninferior to LTuFC, i.e., was either more or similarly effective. Between-group differences were evaluated using an analysis of covariance (ANCOVA) model with baseline diurnal IOP as a covariate and treatment and center as factors. The treatment difference ( $\triangle \mathrm{LTFC}$ $\triangle \mathrm{LTuFC}$ ) and the corresponding $95 \%$ confidence interval (CI) for the difference were calculated. LTFC was considered noninferior to LTuFC if the upper limit of the 2-sided $95 \% \mathrm{CI}$ of the difference was $<1.5 \mathrm{mmHg}$. A sample of 100 subjects per treatment group was estimated to provide at least $85 \%$ power using a 1 -sided test with a $2.5 \%$ significance level.

For secondary efficacy endpoints, the statistical significance of between-group differences in mean 8 AM IOP at weeks $1,2,4,6$, and 8 and mean change in IOP from baseline to week 8 at each measurement time point were analyzed using the ANCOVA method described with regard to the primary endpoint. Between-group differences in proportions of subjects reaching prespecified diurnal IOP levels of $\leq 21, \leq 18, \leq 16$, and $\leq 14 \mathrm{mmHg}$ at week 8 were evaluated using the Cochran-MantelHaenszel test.

Intent-to-treat (ITT) efficacy analyses included all subjects who received study medication, had an IOP measurement at baseline, and had at least one valid postbaseline IOP measurement. Missing efficacy data were imputed using the last observation carried forward
(LOCF) method; baseline values were not carried forward.

\section{Results}

In all, 279 subjects were screened, and 250 completed the 4-week washout period, continued to meet eligibility criteria, and were randomized to study treatment (Figure 1). In the LTFC group, both the safety and ITT populations included the 125 subjects who received treatment. In the $\mathrm{LTuFC}$ group, one subject did not receive study medication and one did not have required IOP measurements; the safety and ITT populations for this group included 124 and 123 subjects, respectively. In both treatment groups, 120 of 125 screened subjects (96\%) completed the study.

Subjects' demographic and baseline clinical characteristics are summarized in Table 1 . With the exception of a somewhat greater proportion of females in the LTFC group ( $53 \%$ vs. $40 \%$, respectively), treatment groups were similar with regard to age, diagnosis, mean baseline IOP, and prior ocular hypotensive medication. Four subjects (3.2\%) in each treatment group had a history of diabetes mellitus; 16 (12.8\%) subjects in the LTFC and 12 (9.6\%) in the LTuFC group had a history of hypertension.

\section{Efficacy}

At baseline, mean diurnal IOP levels were approximately $26 \mathrm{mmHg}$ in both treatment groups (Table 2). Mean IOP reductions of $>8 \mathrm{mmHg}$ from baseline to week 8 were observed in both groups $(\mathrm{P}<0.001$ for each group). The least square mean reduction in diurnal IOP from baseline to week 8 was $8.6 \mathrm{mmHg}$ in LTFC-treated subjects and $8.9 \mathrm{mmHg}$ among those treated with LTuFC. The between-group difference was $0.3 \mathrm{mmHg}$ (95\% CI: $-0.3,1.0$ ); the upper bound of the $95 \%$ CI was $<1.5 \mathrm{mmHg}$, indicating noninferiority of LTFC.

No statistically significant between-group differences were noted in proportions of subjects reaching prespecified percentage mean diurnal IOP levels at week 8 (Figure 2).

The IOP-reducing effect of both the fixed and unfixed combinations was evident at week 1 and was sustained through week 8 . Mean 8 AM IOP levels were reduced significantly $(\mathrm{P}<0.001)$ from baseline at weeks $1,2,4$, 6 , and 8 in both treatment groups, and no betweengroups difference in reduction was statistically significant (Figure 3). At week 8, least square mean IOP reductions from baseline were similar across treatments at all measurement time points (Figure 4).

\section{Adverse events}

The incidence of all-causality treatment-emergent adverse events was low in both treatment groups, with $11.2 \%$ of those receiving LTFC and $6.5 \%$ of subjects 


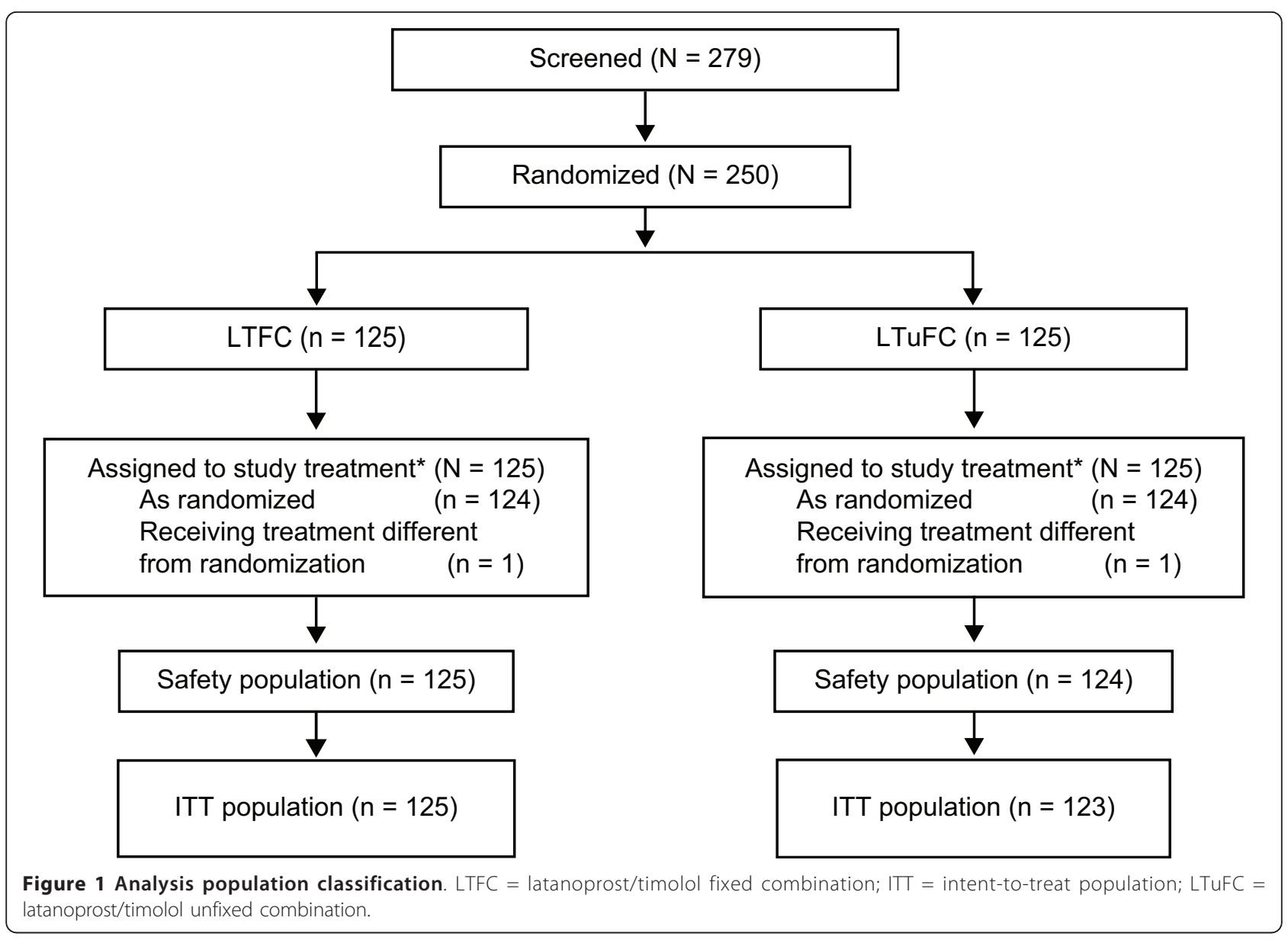

Table 1 Subject characteristics*

\begin{tabular}{lcc}
\hline & LTFC & LTuFC \\
& $\mathbf{N}=\mathbf{1 2 5}$ & $\mathbf{N}=\mathbf{1 2 4}$ \\
\hline Female, n (\%) & $66(52.8)$ & $50(40.3)$ \\
Age, years, mean (range) & $50.0(18-$ & $47.9(17-$ \\
& $75)$ & $74)$ \\
& $87(69.6)$ & $85(68.5)$ \\
Primary open-angle glaucoma, n (\%) & $4.2(0.1-30)$ & $3.1(0.1-33)$ \\
$\quad \begin{array}{l}\text { Duration since diagnosis, years, mean } \\
\text { (range) }\end{array}$ & $38(30.4)$ & $39(31.5)$ \\
Ocular hypertension, n (\%) & $2.7(0.2-25)$ & $2.3(0.2-10)$ \\
$\quad$ Duration since diagnosis, years, mean & & \\
$\quad$ (range) & $25.8 \pm 3.2$ & $26.0 \pm 3.5$ \\
Baseline IOP, mmHg, mean \pm SD ${ }^{\dagger}$ & & \\
Prior medications in $\geq 10 \%$ of subjects, n (\%) & $101(80.8)$ & $93(75.0)$ \\
$\quad$ Brinzolamide & $49(39.2)$ & $42(33.9)$ \\
$\quad$ Carteolol hydrochloride & $28(22.4)$ & $33(26.6)$ \\
$\quad$ Timolol maleate & $22(17.6)$ & $24(19.4)$ \\
$\quad$ Timolol & $15(12.0)$ & $13(10.5)$ \\
$\quad$ Carteolol & & \\
\hline
\end{tabular}

*Safety population.

${ }^{\dagger}$ Includes subjects with data at both baseline and week $8 ; \mathrm{N}=123$ for the LTuFC group.

LTFC = latanoprost/timolol fixed combination; IOP = intraocular pressure; $S D=$ standard deviation; LTuFC = latanoprost/timolol unfixed combination. treated with LTuFC reporting at least one such event (Table 3). No event in either group was considered by an investigator to be severe or serious. Conjunctival hyperemia was the only adverse event to occur in $>3 \%$ of subjects in either group and was reported in $7.2 \%$ of those treated with LTFC and $4.8 \%$ of subjects in the

Table 2 Change in diurnal IOP pressure $(\mathrm{mmHg})$ at week 8 (primary endpoint)*

\begin{tabular}{|c|c|c|}
\hline & $\begin{array}{c}\text { LTFC } \\
\mathrm{N}=125\end{array}$ & $\begin{array}{c}\text { LTuFC } \\
\mathrm{N}=123\end{array}$ \\
\hline Baseline, mean $\pm S D$ & $25.8 \pm 3.2$ & $26.0 \pm 3.5$ \\
\hline Week 8 , mean \pm SD & $17.5 \pm 2.9$ & $17.2 \pm 3.0$ \\
\hline $\begin{array}{l}\text { Change from baseline to week } 8 \text {, mean } \pm \\
\text { SD }\end{array}$ & $-8.3 \pm 3.2$ & $-8.8 \pm 3.8$ \\
\hline$(95 \% \mathrm{Cl})$ & $\begin{array}{l}(-8.9 \text { to } \\
-7.7)\end{array}$ & $\begin{array}{l}(-9.5 \text { to } \\
-8.1)\end{array}$ \\
\hline LS mean change & -8.6 & -8.9 \\
\hline Difference in LS means ( $95 \% \mathrm{Cl}$ ) & \multicolumn{2}{|c|}{$0.3(-0.3$ to 1.0$)$} \\
\hline
\end{tabular}

*Intent-to-treat population.

$\mathrm{Cl}=$ confidence interval; LTFC = latanoprost/timolol fixed combination; IOP = intraocular pressure; $\mathrm{LS}=$ least square; $\mathrm{SD}=$ standard deviation; $\mathrm{LTUFC}=$ latanoprost/timolol unfixed combination. 


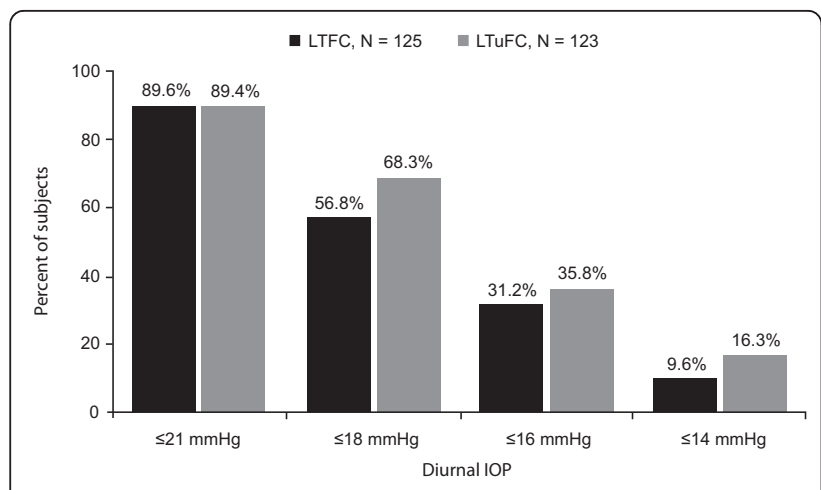

Figure 2 Proportion of subjects achieving prespecified IOP levels at week $\mathbf{8}^{*}$. ${ }^{*}$ ntent-to-treat population. No significant between-group differences based on the Cochran-Mantel-Haenszel test. LTFC = latanoprost/timolol fixed combination; IOP = intraocular pressure; LTUFC = latanoprost/timolol unfixed combination.

LTuFC group. Two subjects in each group discontinued due to an adverse event (LTFC: blurred vision of moderate severity, right bundle branch block; LTuFC: mild chest pain, viral conjunctivitis); one discontinuation in each group was considered to be treatment related (LTFC: blurred vision; LTuFC: mild chest pain). No clinically significant, treatment-emergent abnormalities in vital signs were noted in either treatment group during the study, and there were no clinically important between-group differences in ocular safety assessments or visual field examination findings.

\section{Discussion}

In patients needing two drugs to achieve therapeutic goals, fixed-combination agents such as LTFC may have

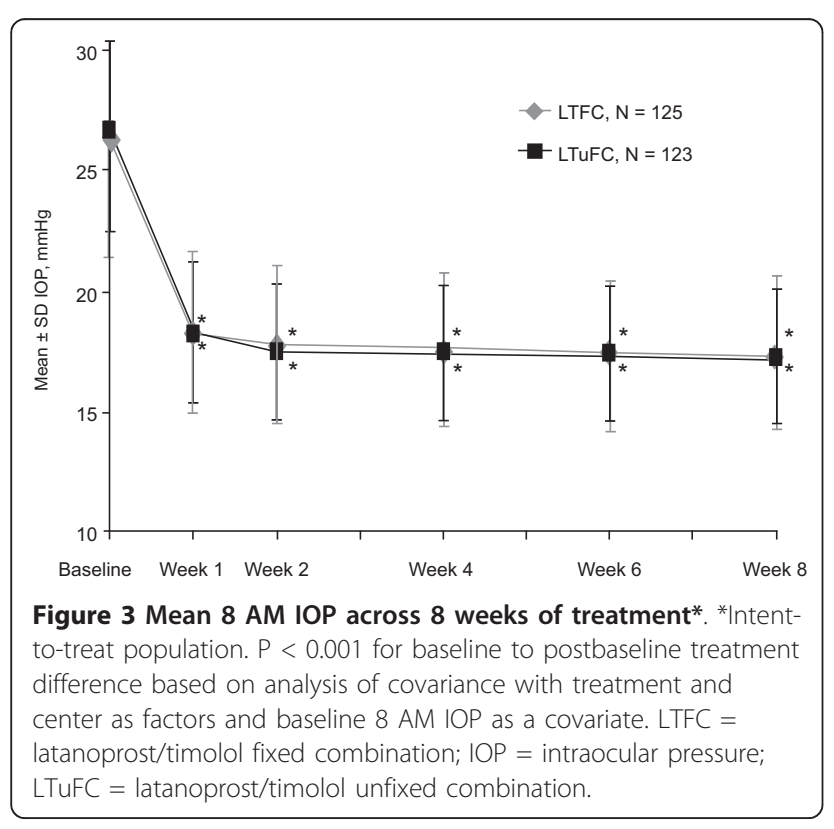

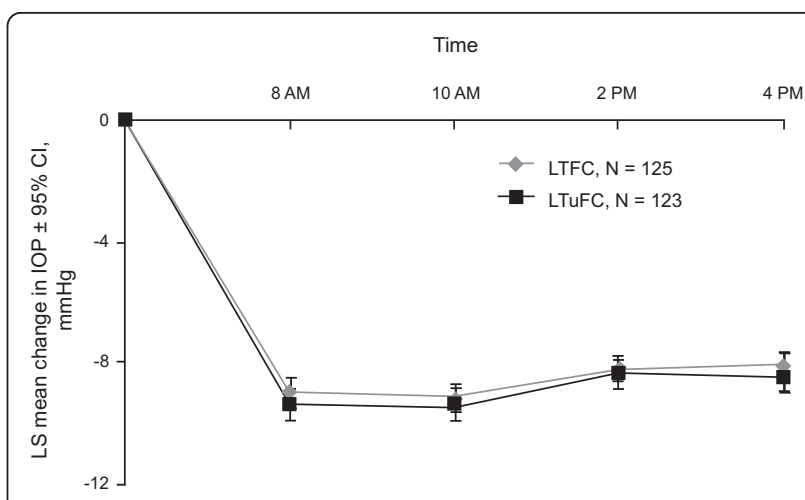

Figure 4 Mean change in IOP from baseline to week 8 at each measurement time point* ${ }^{*}$ Intent-to-treat population. $P>0.17$ for each between-treatment difference based on analysis of covariance with treatment and center as factors and baseline diurnal IOP as a covariate. $L T F C=$ latanoprost/timolol fixed combination; IOP = intraocular pressure; LS = least square; LTuFC = latanoprost/timolol unfixed combination.

advantages over the multiple ocular hypotensives instilled at different times of day. In particular, compliance may be improved with the convenience of oncedaily dosing, an important consideration since medication compliance among patients with POAG and $\mathrm{OH}$ has been shown to be reduced with more complex medication regimens [20-24], and poor adherence has been associated with vision decreases in glaucoma patients $[25,26]$. In addition, once-daily dosing may result in cost savings as well as less exposure to preservatives such as purite, sofZia (Alcon, Fort Worth, Texas), or benzalkonium chloride $[27,28]$.

Table 3 All-causality treatment-emergent adverse events, n (\%)*

\begin{tabular}{lcc}
\hline & LTFC & LTuFC \\
& $\mathbf{N}=\mathbf{1 2 5}$ & $\mathbf{N = 1 2 4}$ \\
\hline Subjects with $\geq 1$ adverse event & $14(11.2)$ & $8(6.5)$ \\
Subjects with $\geq 1$ severe adverse & 0 & 0 \\
Event & & \\
Subjects with $\geq 1$ serious adverse & 0 & 0 \\
Event & & \\
\hline Conjunctival hyperemia & $9(7.2)$ & $6(4.8)$ \\
Visual field defect (mild) & $3(2.4)$ & 0 \\
Eye irritation & $1(0.8)$ & 0 \\
Eyelid cyst & $1(0.8)$ & 0 \\
Eyelid disorder & $1(0.8)$ & 0 \\
Vision blurred & $1(0.8)$ & 0 \\
Right bundle branch block & $1(0.8)$ & 0 \\
Chest pain & 0 & $1(0.8)$ \\
Viral conjunctivitis & 0 & $1(0.8)$ \\
\hline
\end{tabular}

*Safety population.

LTFC = latanoprost/timolol fixed combination; LTuFC = latanoprost/timolol unfixed combination. 
This 8-week, randomized, open-label study in Chinese patients with POAG or $\mathrm{OH}$ whose IOP was insufficiently controlled on a $\beta$-blocker administered either as monotherapy or as part of dual therapy demonstrated that both once-daily LTFC administered in the evening and the unfixed combination of latanoprost dosed in the evening and timolol administered in the morning significantly lowered IOP levels from baseline. In both groups, mean IOP levels were reduced from $26 \mathrm{mmHg}$ at baseline to approximately $17 \mathrm{mmHg}$ at week 8 . For the primary endpoint, the between-group difference in least square mean diurnal IOP reductions from baseline to week 8 was $0.3 \mathrm{mmHg}$ and the upper limit of the $95 \%$ CI was $<1.5 \mathrm{mmHg}$ supporting the noninferiority of LTFC. These findings and the conclusion of noninferiority are similar to results of a randomized, doublemasked trial [19] in which mean diurnal IOP reductions from baseline to week 12 were 8.7 and $9.0 \mathrm{mmHg}$ with LTFC and LTuFC (timolol dosed twice daily), respectively, and the between-treatment difference was 0.3 $\mathrm{mmHg}(95 \% \mathrm{CI}$ : $-0.1,0.7 \mathrm{mmHg}$ P = 0.15). At last measurement (8 weeks herein and 12 weeks in Diestelhorst and Larsson [19]), approximately $90 \%$ of subjects in both treatment groups achieved mean diurnal IOP levels $\leq 21 \mathrm{mmHg}$, and $>30 \%$ had mean diurnal IOPs $\leq 16$ $\mathrm{mmHg}$.

A recent systematic review and meta-analysis of 29 randomized clinical trials of the IOP-lowering effect of prostaglandins combined with topical $\beta$-blockers [29] found equivalent IOP reductions with morning or evening instillation of fixed combinations of timolol and a prostaglandin analog. However, only 24-hour studies are appropriate when addressing morning versus evening administration, and several studies have shown that the relative efficacy of LTFC and latanoprost reflects instillation time. For example, a study by Alm et al [9] as well as several by Konstas et al [30-32] demonstrated that evening dosing of latanoprost and LTFC provided lower daytime IOP levels than morning dosing. A study by Konstas and associates [32] showed that LTFC compared to latanoprost monotherapy, both dosed in the evening, provided a wider margin $(2.5 \mathrm{mmHg}$ more than latanoprost) over 24 hours than the morning dosing used in a regulatory trial [33]. In another crossover study [34], 24-hour IOP fluctuation was significantly lower with LTFC dosed in the evening compared with timolol alone $(3.2 \mathrm{mmHg}$ vs $4.4 \mathrm{mmHg}$, respectively; $\mathrm{P}$ $=0.003)$. Finally, a direct 24-hour IOP comparison between morning and evening administration of LTFC in POAG patients found that evening dosing provided more effective IOP control [35].

In addition to the issue of administration time, no study of LTFC has included evenly distributed trough and peak measurements [29]. Moreover, although timolol administered once daily has been shown to achieve maximum IOP reduction [36], the impact of circadian rhythm remains to be clarified. Peak IOP values in the morning and nadir values in the evening have been reported for both healthy elderly volunteers [37] and for untreated individuals with glaucoma [38]. In the current study, IOP assessments were limited to the period between $8 \mathrm{AM}$ and $4 \mathrm{PM}$, which coincided with the first 8 hours after the morning administration of timolol in the unfixed combination.

The meta-analysis [29] found that greater IOP lowering occurred with concomitant timolol twice daily and latanoprost once daily than with LTFC, a difference that may reflect the omission of a timolol dose with the fixed combination. Herein, timolol was administered once daily in the morning in the LTuFC arm rather than twice daily as is more typical with unfixed regimens. Instillation of one dose of timolol in the morning in both treatment arms may explain, in part, the relatively small between-group difference in mean IOP reduction.

Consistent with the results of previous studies $[19,27,39-41]$, both the fixed and unfixed combinations of latanoprost/timolol were well tolerated. Rates of treatment-emergent adverse events were somewhat lower in the present study than reported by Diestelhorst and Larsson [19] possibly reflecting the difference in followup ( 8 weeks vs 12 weeks, respectively). In the present study, only one adverse event (conjunctival hyperemia) occurred in $>3 \%$ of subjects in each treatment group, and only two subjects in each group discontinued due to treatment-related adverse events. There were no clinically important between-group differences in treatment-emergent changes in ocular safety assessments. It is important to note, however, that the duration of the present study was too short to identify possible longterm adverse treatment effects.

This is the first study to compare the efficacy and tolerability of LTFC with that of LTuFC in a Chinese population, a population that represents an increasingly large proportion of individuals with POAG or $\mathrm{OH}$ worldwide. The study is limited by its open-label design. However, the randomization of subjects and the assessment of outcomes at multiple visits and the fact that our results closely parallel those of a prior doublemasked study [19] suggest that the impact of the openlabel design may have been minimal. The research also was limited by its short time frame since follow-up periods of several years would be needed to assess the progression of glaucomatous damage. Although Watson et al [12] found that POAG patients treated with latanoprost monotherapy experienced a significantly greater mean IOP reduction than similarly treated $\mathrm{OH}$ patients (9.4 $\mathrm{mmHg}$ vs $7.1 \mathrm{mmHg}$, respectively), such an analysis 
was not prespecified in the present study; future research might profitably compare differences between these diagnosis groups in Chinese patients.

\section{Conclusion}

Single nighttime dosing with LTFC is well tolerated and at least as effective as concomitant administration of latanoprost and timolol each administered once daily. The benefits of combination treatment argue for its consideration by clinicians when two drugs are needed to meet therapeutic goals.

\section{Acknowledgements}

Editorial support, including revising the draft based on author comments, and styling the paper for journal submission, was provided by Jane G. Murphy, PhD, of Zola Associates, and was funded by Pfizer Inc. Xalacom Study Group in China:

Beijing University People's Hospital, Beijing, China: Xiao-Xin Li, Li-Xin Li, ZeQin Ren, Xian-Ru Hou.

Chinese Academy of Medical Sciences, Peking Union Medical College Hospital, Beijing, China: Jia-Liang Zhao, Xiao-Li Liu.

Eye \& ENT Hospital of Fudan University, Shanghai, China: Xing-Huai Sun.

Shao-Hong Qian, Xiang-Mei Kong, Jing Yao.

Pfizer Investment Co., Ltd., China, Medical Affairs: Zheng Zhong

Shanghai Jiaotong University, Xin Hua Hospital of Medical School, Shanghai, China: Yao-Hua Sheng, Wei-Hua Xu, Yu-Qun Zhang, Jie Cen.

$X i$, an Jiao Tong University, 2nd Hospital, Xi'an, China: Nai-Xue Sun, Jian-Ming Wang, Jing Wang, Feng Wang.

Zhe Jiang University, 1st Hospital, Hangzhou, China: Yu-Min Li, Xiao-Yu

Wang, Jia-Xun Yan, Li-Ping Shen.

Zhe Jiang University, 2nd Hospital, Hangzhou, China: Ke Yao, Ren-Yi Wu, JinFu Yin, Meng-Zheng Xuan.

Zhong Shan Ophthalmic Center, Sun Yat-Sen University, Guangzhou, China: Jian Ge, Mei Wang, Ming-Kai Lin, Sheng-Song Huang.

The research was supported by Pfizer Investment Co., Ltd., China.

\section{Author details}

'Chinese Academy of Medical Sciences, Peking Union Medical College Hospital, Beijing, China. ${ }^{2}$ Zhong Shan Ophthalmic Center, Sun Yat-Sen University, Guangzhou, China. 'BBeijing University People's Hospital, Beijing, China. ${ }^{4}$ Zhe Jiang University, 1st Hospital, Hangzhou, China. ${ }^{5}$ Shanghai Jiaotong University, Xin Hua Hospital of Medical School, Shanghai, China. ${ }^{6}$ Xi'an Jiao Tong University, 2nd Hospital, Xi'an, China. ${ }^{7} E y e$ \& ENT Hospital of Fudan University, Shanghai, China. ${ }^{8}$ Zhe Jiang University, 2nd Hospital, Hangzhou, China. ${ }^{9}$ Medical Affairs, Pfizer Investment Co. Ltd., China.

\section{Authors' contributions}

JLZ was the principal investigator of the study. He made substantial contributions to the conception and design, acquisition of data, and analysis and interpretation of data for this study. He participated in drafting the article and in the critical revision of the manuscript for important intellectual content.

$J G, X X L, Y M L, Y H S, N X S, X H S$, and $K Y$ were the principal investigators in each of the medical centers involved in the study. They participated in the design, acquisition and interpretation of data, and critical revision of the manuscript for important intellectual content. ZZ participated in the analysis and interpretation of data and in the critical revision of the manuscript for important intellectual content. All authors read and approved the final manuscript.

Members of the Xalacom Study Group in China participated in the study. The results of this study were presented in part at the IIV Congress of the Asian-Oceanic Glaucoma Society and 2008 National Congress of the Chinese Glaucoma Society, Dec.5-7, 2008, Guangzhou, China.

\section{Competing interests}

Dr. Zheng Zhong is an employee of Pfizer Investment Co., Ltd., China. The other authors have no proprietary or commercial interest in any of the materials discussed in this article.

Received: 2 March 2011 Accepted: 19 August 2011

Published: 19 August 2011

\section{References}

1. Population Division of the Department of Economic and Social Affairs of the United Nations Secretariat: World Population Prospects: The 2004 Revision. Highlights New York: United Nations; 2005 [http://www.un.org/ esa/population/publications/WPP2004/2004Highlights_finalrevised.pdf], Accessed January 18, 2011.

2. Zhou Q, Friedman DS, Lu H, Duan X, Liang Y, Yang X, Wang F, Wang N: The epidemiology of age-related eye diseases in Mainland China. Ophthalmic Epidemiol 2007, 14:399-407.

3. Hoyng PF, van Beek LM: Pharmacological therapy for glaucoma: a review. Rugs 2000, 59:411-434.

4. Hurvitz LM, Kaufman PL, Robin AL, Weinreb RN, Crawford K, Shaw B: New developments in the drug treatment of glaucoma. Drugs 1991, 41:514-532.

5. Marquis RE, Whitson JT: Management of glaucoma: focus on pharmacological therapy. Drugs Aging 2005, 22:1-21

6. Vass C, Hirn C, Sycha T, Findl O, Bauer P, Schmetterer L: Medical interventions for primary open angle glaucoma and ocular hypertension. Cochrane Database Syst Rev 2007, 4:CD003167.

7. Kobelt-Nguyen G, Gerdtham UG, Alm A: Costs of treating primary openangle glaucoma and ocular hypertension: a retrospective, observational two-year chart review of newly diagnosed patients in Sweden and the United States. J Glaucoma 1998, 7:95-104.

8. Toris CB, Camras CB, Yablonski ME: Effects of PhXA41, a new prostaglandin F2 alpha analog, on aqueous humor dynamics in human eyes. Ophthalmology 1993, 100:1297-1304.

9. Alm A, Stjernschantz J, Scandinavian Latanoprost Study Group: Effects on intraocular pressure and side effects of $0.005 \%$ latanoprost applied once daily, evening or morning. A comparison with timolol. Ophthalmology 1995, 102:1743-1752.

10. Alm A, Widengård I, Kjellgren D, Söderström $M$, Friström B, Heijl A, Stjerschantz J: Latanoprost administered once daily caused a maintained reduction of intraocular pressure in glaucoma subjects treated concomitantly with timolol. Br J Ophthalmol 1995, 79:12-16.

11. Camras CB, United States Latanoprost Study Group: Comparison of latanoprost and timolol in patients with ocular hypertension and glaucoma: a six-month masked, multicenter trial in the United States. Ophthalmology 1996, 103:138-147.

12. Watson P, Stjernschantz J, Latanoprost Study Group: A six-month, randomized, double-masked study comparing latanoprost with timolol in open-angle glaucoma and ocular hypertension. Ophthalmology 1996, 103:126-137.

13. Hedman K, Larsson LI: The effect of latanoprost compared with timolol in African-American, Asian, Caucasian, and Mexican open-angle glaucoma or ocular hypertensive patients. Surv Ophthalmol 2002, 47(Suppl 1):S77-89.

14. American Academy of Ophthalmology: Primary Open-Angle Glaucoma, Preferred Practice Pattern. San Francisco: American Academy of Ophthalmology 2005 [http://www.aao.org/ppp], Accessed: January 18, 2011.

15. European Glaucoma Society Terminology and Guidelines for Glaucoma: Savona, Italy: DOGMA; 32008 [http://www.eugs.org/eng/EGS_guidelines. asp], Accessed August 10, 2011

16. Bucci MG, the Italian Latanoprost Study Group: Intraocular pressurelowering effects of latanoprost monotherapy versus latanoprost or pilocarpine in combination with timolol: a randomized, observer-masked multicenter study in patients with open-angle glaucoma. J Glaucoma 1999, 8:24-30.

17. Lee PY, Shao H, Camras CB, Podos SM: Additivity of prostaglandin F2 alpha-1-isopropyl ester to timolol in glaucoma patients. Ophthalmology 1991, 98:1079-1082.

18. Rulo AH, Greve EL, Hoyng PF: Additive effect of latanoprost, a prostaglandin F2 alpha analogue, and timolol in patients with elevated intraocular pressure. Br J Ophthalmol 1994, 78:899-902. 
19. Diestelhorst M, Larsson LI, European-Canadian Latanoprost Fixed Combination Study Group: A 12-week, randomized, double-masked, multicenter study of the fixed combination of latanoprost and timolol in the evening versus the individual components. Ophthalmology 2006, 113:70-76.

20. Gurwitz JH, Glynn RJ, Monane M, Everitt DE, Gilden D, Smith N, Avorn J: Treatment for glaucoma: adherence by the elderly. Am J Public Health 1993, 83:711-716.

21. Patel SC, Spaeth GL: Compliance in patients prescribed eyedrops for glaucoma. Ophthalmic Surg 1995, 26:233-236.

22. Robin AL, Novack GD, Covert DW, Crockett RS, Marcic TS: Adherence in glaucoma: objective measurements of once-daily and adjunctive medication use. Am J Ophthalmol 2007, 144:533-540.

23. Higginbotham EJ, Hansen J, Davis EJ, Walt JG, Guckian A: Glaucoma medication persistence with a fixed combination versus multiple bottles. Curr Med Res Opin 2009, 25:2543-2547.

24. Chawla A, McGalliard JN, Batterbury M: Use of eyedrops in glaucoma: How can we help to reduce non-compliance? Acta Ophthalmol Scand 2007, 85:464.

25. Stewart WC, Chorak RP, Hunt HH, Sethuraman G: Factors associated with visual loss in patients with advanced glaucomatous changes in the optic nerve head. Am J Ophthalmol 1993, 116:176-181.

26. Rossi GCM, Pasinetti GM, Scudeller, Radaelli R, Bianchi PE: Do adherence rates and glaucomatous visual field progression correlate? Eur J Ophthalmol 2010.

27. Higginbotham EJ, Olander KW, Kim EE, Grunden JW, Kwok KK, Tressler CS, United States Fixed-Combination Study Group: Fixed combination of latanoprost and timolol vs individual components for primary openangle glaucoma or ocular hypertension: a randomized, double-masked study. Arch Ophthalmol 2010, 128:165-172.

28. Baudouin C: Detrimental effect of preservatives in eyedrops: implications for the treatment of glaucoma. Acta Ophthalmol 2008, 92:1275-1282.

29. Webers CA, Beckers HJ, Zeegers MP, Nuijts RM, Hendrikse F, Schouten JS: The intraocular pressure-lowering effect of prostaglandin analogs combined with topical beta-blocker therapy: a systematic review and meta-analysis. Ophthalmology 2010, 117:2067-2074.

30. Konstas AG, Maltezos AC, Gandi S, Hudgins AC, Stewart WC: Comparison of 24-hour intraocular pressure reduction with two dosing regimens of latanoprost and timolol maleate in patients with primary open-angle glaucoma. Am J Ophthalmol 1999, 128:15-20.

31. Konstas AG, Nakos E, Tersis I, Lallos NA, Leech JN, Stewart WC: A comparison of once-daily morning vs evening dosing of concomitant latanoprost/timolol. Am J Ophthalmol 2002, 133:753-757.

32. Konstas AG, Boboridis K, Tzetzi D, Kallinderis K, Jenkins JN, Stewart WC: Twenty-four-hour control with latanoprost-timolol-fixed combination therapy vs latanoprost therapy. Arch Ophthalmol 2005, 123:898-902.

33. Pfeiffer N, European Latanoprost Fixed Combination Study Group: A comparison of the fixed combination of latanoprost and timolol with its individual components. Graefes Arch Clin Exp Ophthalmol 2002, 240:893-899.

34. Konstas AG, Lake S, Economou Al, Kaltsos K, Jenkins JN, Stewart WC: 24Hour control with a latanoprost-timolol fixed combination vs timolol alone. Arch Ophthalmol 2006, 124:1553-1557.

35. Takmaz T, Aşik S, Kürkçüoğ.ggglu P, Gurdal C, Can I: Comparison of intraocular pressure lowering effect of once daily morning vs evening dosing of latanoprost/timolol maleate combination. Eur J Ophthalmol 2008, 18:60-65.

36. Letchinger SL, Frohlichstein D, Glieser DK, Higginbotham EJ, Wilensky JT, Viana MA, Zeimer R: Can the concentration of timolol or the frequency of its administration be reduced? Ophthalmology 1993, 100:1259-1262.

37. Kida T, Liu JH, Weinreb RN: Effects of aging on corneal biomechanical properties and their impact on 24-hour measurement of intraocular pressure. Am J Ophthalmol 2008, 146:567-572.

38. Liu JH, Zhang X, Kripke DF, Weinreb RN: Twenty-four-hour intraocular pressure pattern associated with early glaucomatous changes. Invest Ophthalmol Vis Sci 2003, 44:1586-1590.

39. Diestelhorst M, Larsson LI, European Latanoprost Fixed Combination Study Group: A 12 week study comparing the fixed combination of latanoprost and timolol with the concomitant use of the individual components in patients with open angle glaucoma and ocular hypertension. $\mathrm{Br} J$ Ophthalmol 2004, 88:199-203.
40. Higginbotham EJ, Feldman R, Stiles M, Dubiner H, Fixed Combination Investigative Group: Latanoprost and timolol combination therapy vs monotherapy: one-year randomized trial. Arch Ophthalmol 2002, 120:915-922.

41. Palmberg P, Kim EE, Kwok KK, Tressler CS, Latanoprost/Timolol Study: A 12week, randomized, double-masked study of fixed combination latanoprost/timolol versus latanoprost or timolol monotherapy. Eur J Ophthalmol 2010, 20:708-718.

\section{Pre-publication history}

The pre-publication history for this paper can be accessed here: http://www.biomedcentral.com/1471-2415/11/23/prepub

doi:10.1186/1471-2415-11-23

Cite this article as: Zhao et al:: Comparative efficacy and safety of the fixed versus unfixed combination of latanoprost and timolol in Chinese patients with open-angle glaucoma or ocular hypertension. BMC Ophthalmology 2011 11:23.

\section{Submit your next manuscript to BioMed Central and take full advantage of:}

- Convenient online submission

- Thorough peer review

- No space constraints or color figure charges

- Immediate publication on acceptance

- Inclusion in PubMed, CAS, Scopus and Google Scholar

- Research which is freely available for redistribution

Submit your manuscript at www.biomedcentral.com/submit
C Biomed Central 